Proceedings

\title{
New strains of bacteria that degrade aromatic compounds act as antagonists of highly active phytopathogens $^{+}$
}

Tatiana O. Anokhina ${ }^{1}$, Tatiana Z. Esikova ${ }^{2}$, Tatiana N. Abashina ${ }^{3}$, Nataliya E. Suzina ${ }^{4}$ and Inna P. Solyanikova ${ }^{5 *}$

1 Laboratory of Plasmid Biology, Institute of Biochemistry and Physiology of Microorganisms, Pushchino Scientific Center for Biological Research of the Russian Academy of Sciences (PSCBR RAS); e-mail: to_anohina@rambler.ru

2 Laboratory of Plasmid Biology, Institute of Biochemistry and Physiology of Microorganisms, Pushchino Scientific Center for Biological Research of the Russian Academy of Sciences (PSCBR RAS); e-mail: das3534@rambler.ru

3 Laboratory of Cytology of Microorganisms, Institute of Biochemistry and Physiology of Microorganisms, Pushchino Scientific Center for Biological Research of the Russian Academy of Sciences (PSCBR RAS); email: tnabashina@gmail.com

4 Laboratory of Cytology of Microorganisms, Institute of Biochemistry and Physiology of Microorganisms, Pushchino Scientific Center for Biological Research of the Russian Academy of Sciences (PSCBR RAS); email: suzina_nataliya@rambler.ru

5 Laboratory of Microbial Enzymology, Institute of Biochemistry and Physiology of Microorganisms, Pushchino Scientific Center for Biological Research of the Russian Academy of Sciences (PSCBR RAS); email: Innas@ibpm.pushchino.ru

* Correspondence: Innas@ibpm.pushchino.ru

+ Presented at the 1st International Electronic Conference on Microbiology 02-30 November 2020; Available online: https:// ecm2020.sciforum.net/.

Published: 02 November 2020

\begin{abstract}
The intensive development of agriculture leads to depletion of land, a decrease in crop yields and in plant resistance to diseases. A large number of fertilizers and pesticides are currently used to solve these problems. Chemicals can enter the soil, penetrate into the groundwater and agricultural plants. Therefore, the primary task is to intensify agricultural production without causing additional damage to the environment. This problem can be partially solved using microorganisms with target properties. Microorganisms that combine several useful traits are especially valuable. The aim of this work was to search for new microbial strains that possess a complex technologically significant potential, such as increasing the bioavailability of nutrients, phytostimulation, antifungal effect and degradation of pesticide residues and other xenobiotics. Few isolated Bacillus and Pseudomonas strains were characterized by high activity against fungal phytopathogens. One of the bacterial strains identified as Bacillus sp. on the basis of the 16S rRNA gene sequence was characterized by an unusual cellular morphology and development cycle, significantly different from all previously described bacteria of this genus. All isolated bacteria are capable of benzoate degradation, as a sign of the ability to degrade aromatic compounds. Isolated strains were shown to be perspective agents in biotechnologies.
\end{abstract}

Keywords: xenobiotics; degradation; soils; bioremediation; phytopathogens; plant protection

\section{Introduction}

The continuously increasing level of environmental pollution leads to the need for the development of biotechnologies for environment remediation. The soil is an extremely complex 
habitat, rich in microorganisms and characterized by a high diversity of microbial communities. The number of microorganisms is several billion cells per gram of soil, and biodiversity reaches hundreds of thousands of species of bacteria and archaea [1]. The rhizosphere is the most microorganism-rich part of the soil due to the mutual positive influence of plants and microorganisms on each other.

The soil is not only a depository of biological diversity, but also a kind of biochemical reactor, since microorganisms constantly carry out many enzymatic reactions / processes, including the degradation of xenobiotics and pollutants of natural origin. The microbial community is the most important ecological indicator of "soil health", which reflects the state of the soil biocenosis and its response to various influences, including pollution by toxic substances. Soils of agricultural importance are subjected to colossal anthropogenic impact, which leads to a change in their mineral composition, a decrease in the content of soil organic matter, the accumulation of pesticides, the spread of pesticide-resistant phytopathogenic microorganisms and, ultimately, to the depletion of the species and numerical composition of agrobiocenoses.

Among the research fields of soil microbiology, it is necessary to note such areas as the assessment of the general state of microbial systems, seasonal fluctuations in the biomass of microbiocenosis, the spread of microorganisms of various taxonomic groups in soils of different types [2], as well as the study of the effect of anthropogenic load on the change in abundance and the diversity of soil microorganisms [3]. Special attention is paid to the study of rhizosphere microorganisms, including bacteria that stimulate plant growth (plant growth promoting rhizosphere bacteria) [4,5]. In this case, not only microbial diversity is investigated, but also the features of the interaction of microorganisms with the host plant are revealed. The mechanisms of the positive effect of bacteria on plants can be roughly divided into two types: direct stimulation of plant growth through the synthesis of phytohormones and improvement of their mineral nutrition; indirect stimulation of plant growth by inhibiting the growth of soil phytopathogenic fungi and bacteria [6].

In recent decades, biological preparations based on a variety of microorganisms and their metabolites are increasingly used to protect plants from pathogens. $[7,8]$. The active agents of biopreparations are components of natural biocenoses, which explains their safety for the environment. The positive aspects of using microbiological preparations are their environmental friendliness, including a decrease in the chemical load on agroecosystems, low cost, the possibility of combining them with chemical plant protection agents, and a fairly high biological effectiveness of action. The use of biological products increases the yield of agricultural crops by $10-40 \%$ (depending on the type of plants), improves the quality of products and their nutritional and feed value. On the Russian market there are a number of such well-proven microbiological biological products, including inoculants for legumes (Rizotorfin), biofungicides (Flavobacterin, Rizoplan, Gamair, Glyocladin), growth stimulants (Mizorin, Agrophil, Bizcoloinci) $[9,10]$.

Currently, the urgent tasks for increasing the productivity of agricultural crops are the isolation of new effective strains of bacteria to protect and stimulate plant growth, the study of their influence on plant development in various conditions, including in areas contaminated with toxicants, including pesticides. The aim of this work was to search for new microbial strains that are applicable for agricultural production and possess a complex technologically significant potential.

\section{Material and methods}

\subsection{Bacterial strains and cultivation conditions}

Bacterial strains were isolated from the chernozem soil collected in Belgorod region, Russia. These soils are used as agricultural soils with a crop rotation. To isolate strains, the selected samples $(1 \mathrm{~g})$ were resuspended in mineral medium of the following composition $(\mathrm{g} / \mathrm{L})$ : $\mathrm{Na}_{2} \mathrm{HPO}_{4}, 0.73$; $\mathrm{KH}_{2} \mathrm{PO}_{4}, 0.35 ; \mathrm{MgSO}_{4} \times 7 \mathrm{H}_{2} \mathrm{O}, 0.1 ; \mathrm{NaHCO}_{3}, 0.25 ; \mathrm{MnSO}_{4} \times 5 \mathrm{H}_{2} \mathrm{O}, 0.002 ; \mathrm{NH}_{4} \mathrm{NO}_{3}, 0.75 ; \mathrm{FeSO}_{4} \times 7 \mathrm{H}_{2} \mathrm{O}$, 0.02 (Reakhim, Россия); pH 7.2. Soil suspension were diluted to $10^{-8}$ and $100 \mu \mathrm{L}$ of diluted in $10^{-6}-10^{-8}$ samples were plated on mineral agarized medium with $200 \mathrm{mg} / \mathrm{l}$ of benzoate $\mathrm{Na}$ as the sole sources 
of carbon and energy. Bacteria were grown at $28^{\circ} \mathrm{C}$. Grown colonies were picked up and transferred on sterile agarized Luria-Bertani (LB) medium [11].

Strains of phytopathogenic fungi Gaeumannomyces graminis var. tritici, Fusarium graminearum and Rhizoctonia solani were used as test cultures to study antagonistic activity. For the cultivation of fungi, Kanner's medium was used [12].

\subsection{Sequencing and phylogenetic analysis of $16 S \mathrm{rRNA}$ genes}

Genomic DNA was prepared by Fungal/Bacterial DNA Kit (ZymoResearch, USA) according to the protocol. Purified DNA samples were used for amplification of a nearly complete sequence of the $16 \mathrm{~S}$ rRNA gene using two bacterial universal primers 27F (5'-AGAGTTTGATCMTGGCTCAG) and 1492R (5'- TACGGYTACCTTGTTACGACTT) [13]. The PCR products were purified using Zymoclean Gel DNA Recovery Kit (ZymoResearch, USA) and sequenced with an ABI Prism 373 3130XL automatic sequencer (Applied Biosystems, USA).

Preliminary phylogenetic analysis of the nucleotide sequences of the 16S rRNA genes was carried out using the GenBank database (NCBI) and the BLAST software package (http://ncbi.nlm.nih.gov). For more accurate phylogenetic positioning of the investigated strain, the produced 16S rRNA gene sequence was aligned with the respective sequences of the closest bacterial species using the CLUSTAL W program [14].

\subsection{Microscopy}

Light microscopy under phase contrast was carried out under a Nikon Eclipse Ci microscope (Nikon, Japan) equipped with a Jenoptic ProgResSpeedXTcore5 camera (Jenoptic, Germany).

To perform electron microscopy of thin sections, the cell biomass was prefixed with $1.5 \%(\mathrm{v} / \mathrm{v})$ glutaraldehyde solution in $0.05 \mathrm{M}$ cacodylate buffer ( $\mathrm{pH} 7.2$ ) at $4^{\circ} \mathrm{C}$ for $1 \mathrm{~h}$. After three washings with the same buffer, the material was additionally fixed with $1 \% \mathrm{OsO}_{4}$ in $0.05 \mathrm{M}$ cacodylate buffer at $20^{\circ} \mathrm{C}$ for $3 \mathrm{~h}$. After dehydration, the material was embedded into epoxy resin Epon 812. Ultrathin sections were made on an 8800 ULTROTOME III (Sweden). The sections were mounted on copper grids covered with a Formvar film, contrasted with uranyl acetate ( $3 \%$ solution in $70 \%$ ethanol) for $30 \mathrm{~min}$, and then stained with lead citrate [15] at $20^{\circ} \mathrm{C}$ for $4-5 \mathrm{~min}$. The sections were examined in a JEM- 1200EX (JEOL, Japan) electron microscope at an $80 \mathrm{kV}$ accelerating voltage.

\subsection{Determination of the antagonistic activity of soil strains against phytopathogenic fungi}

Soil strains were grown in liquid LB medium for $16-20 \mathrm{~h}$. An aliquot of the culture $(5 \mu \mathrm{L})$ was applied to the surface of Kanner's agar medium and then incubated at $24^{\circ} \mathrm{C}$ for 2 days. Then, a segment of mycelium ( $8-10 \mathrm{~mm}$ in diameter) of a phytopathogenic fungus was placed in the center of a Petri dish. Fungal mycelium was preliminarily grown in Kanner's medium at room temperature for 7 days. Petri dishes were incubated at room temperature for 7-10 days, after which the presence of a zone of inhibition of mycelium growth was visually assessed. The size of the growth inhibition zone was measured from the edge of the bacterial colony. P. chlororaphis strain BS1393, which produces a number of antibiotic active compounds, was used as a control [16].

\subsection{Characterization of the biochemical properties of the tested strains}

To determine the spectrum of utilized substrates and enzyme activities of the isolates, we used the Analytical Profile Index (API) $20 \mathrm{E}$ and $\mathrm{CH} 50$ strips (bioMerieux, France) according to the manufacturer's instructions, as well as colored Hiss medium with carbohydrates that contained the following (g/L): peptone, 10.0; $\mathrm{NaCl}$, 5.0; carbohydrate, 7.0; and 1.6\% bromothymol blue solution, 1.0 $\mathrm{mL}$.

\section{Results and Discussion}

\subsection{Antagonistic activity}


By the method of direct inoculation on agar medium with sodium benzoate as the sole growth substrate, 30 strains of bacteria were isolated, differing in colony morphology. When these strains were cultivated on a mineral medium with benzoate, no yellow color of the medium was observed in any case. This indicates that the isolated cultures implement the ortho, and not the meta pathway of cleavage of catechol. The latter is the most frequently formed intermediate during microbial degradation of benzoate. Microorganisms capable of degrading benzoate, as a rule, convert some other aromatic compounds. Therefore, this metabolic activity can be used as a marker factor in the selection of pollutant-degrading strains. All isolates were tested for antagonistic activity against the phytopathogenic fungi Gaeumannomyces graminis var. tritici, Fusarium graminearum and Rhizoctonia solani. Of these, 4 strains (designated as 3, 18, 27, 28) exhibited pronounced antifungal activity. Isolate 3 had the greatest activity against all used phytopathogenic fungi. Bacteria 18, 27 and 28 suppressed the growth of F. graminearum only (Table 1).

Table 1. Antagonistic activity of soil strains against phytopathogenic fungi.

\begin{tabular}{ccccc}
\hline \multirow{2}{*}{ Strain } & \begin{tabular}{c} 
Identification \\
according 16S \\
\cline { 3 - 5 }
\end{tabular} & \multicolumn{3}{c}{ Phytopathogen suppression zone, $\mathbf{m m}$} \\
\cline { 3 - 5 } & rRNA gene & F. graminearum & R. solani & G. g. tritici \\
\hline 3 & P. chlororaphis & $3 \pm 1$ & $2 \pm 1$ & $2 \pm 1$ \\
18 & B. subtilis & $\leq 1$ & -1 & - \\
27 & B. subtilis & $\leq 2$ & - & - \\
28 & B. subtilis & $\leq 2$ & - & - \\
P. chlororaphis BS1393 & & $2 \pm 1$ & $3 \pm 1$ & $2 \pm 1$ \\
\hline
\end{tabular}

${ }^{1}$ Zone of suppression of growth of test microorganism is absent.

\subsection{Microscopic studies}

All 30 isolated cultures were microscopically examined for purity and morphological evaluation. Based on the results of tests for antifungal activity and microscopy, 5 cultures were selected for further work. Morphometric analysis of phase contrast images of the cells of the studied bacterial strains made it possible to estimate their size and characterize a number of unique morphological features. Vegetative cells of studied bacterial strains 18, 27 and 28 are represented by large rods of regular shape with the following sizes (Fig. $1 \mathrm{a}-\mathrm{c}$ ): strain 27: 3.5 - $5 \times 0.7-0.9 \mu \mathrm{m}$; strain 28: 2.5 - $3.5 \times$ $0.9-1.0 \mu \mathrm{m}$; strain 18: $3.5-5 \times 0.8-1.0 \mu \mathrm{m}$. Vegetative cells of bacteria 3 have characteristic sizes 1.2 $-1.8 \times 0.7-0.9 \mu \mathrm{m}$ (Fig. 1d). In strain 25 , the cells were characterized by an unusual shape and greatly varied in size (2.5-4 $\mu \mathrm{m}$ long and 0.8-1 $\mu \mathrm{m}$ wide) depending on the age of the culture.Strain 25 was selected for further work due to its unique morphological features.

\subsection{Strains identification}

The nucleotide sequences of $16 \mathrm{~S}$ rRNA gene ( 1400 base pairs) for strains 18, 27, 28 were determined. The sequences of $16 \mathrm{~S}$ rRNA gene in all strains differed in single nucleotide substitutions ( 99.2\% identity) and, according to the results of phylogenetic analysis, strains 18, 27, 28 belong to the class Bacceliaceae, genus Bacillus. The strains showed the highest sequence similarity $(99.4 \%)$ with the type strain of this species Bacillus subtilis subsp. subtilis ATCC $6051^{\mathrm{TM}}$. 


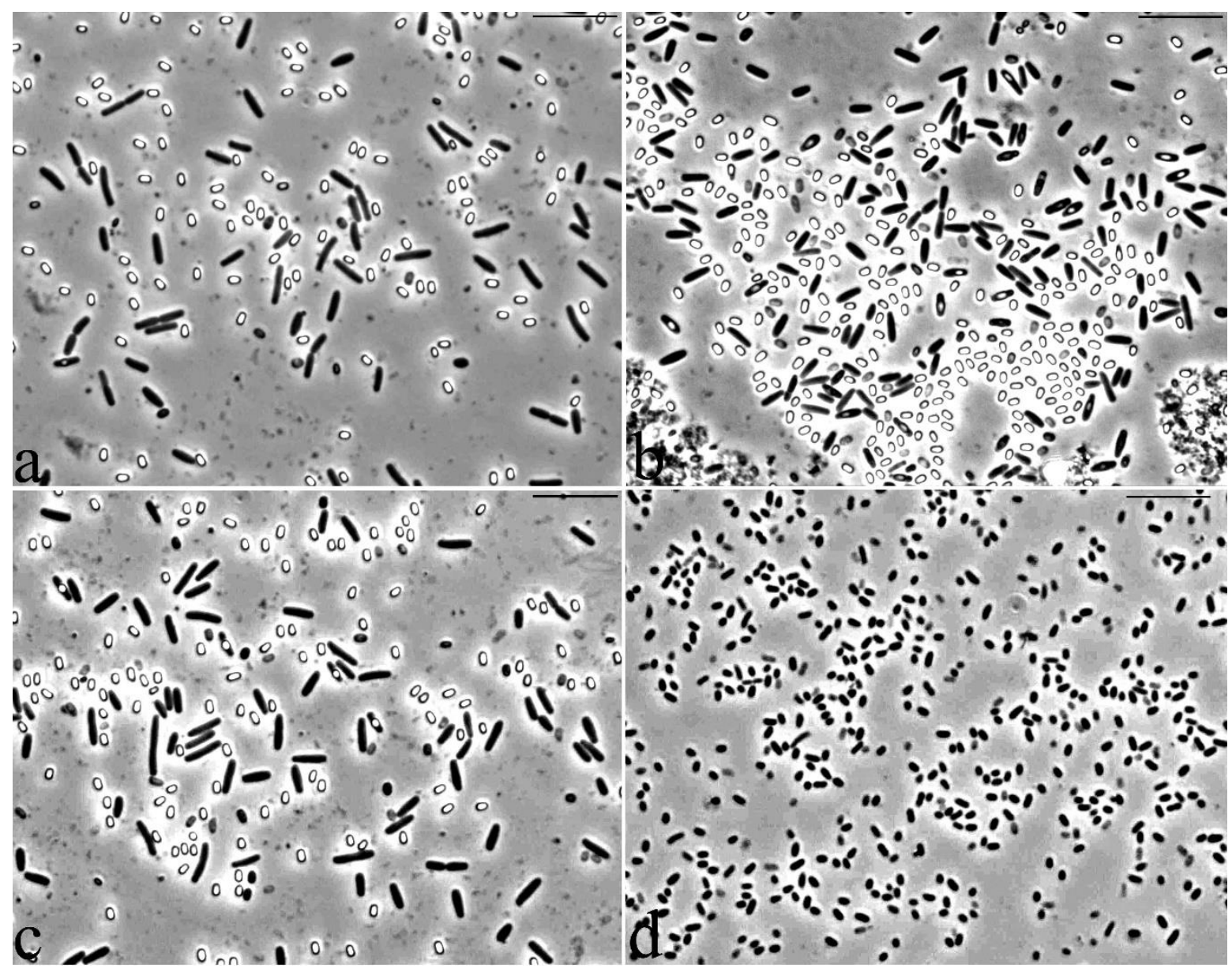

Figure 1. Cells of the studied strains in the exponential growth phase. a - B. subtilis 27; b - B. subtilis 28; c - B. subtilis 18; d - P. chlororaphis 3. Light microscopy. Phase contrast. Bar - $10 \mu \mathrm{m}$.

The closeness of strains 18,27, and 28 to each other and to the Bacillus subtilis species is also confirmed by biochemical characteristics (API tests $20 \mathrm{E}$ and $\mathrm{CH} 50$ ). Bacillus spp. 18, 27, and 28 differed from each other and from the type B. subtilis ATCC $6051^{\mathrm{TM}}$ strain by no more than 5 out of 50 phenotypic characters, which indicates their closeness and possible belonging to this species. Nevertheless, since no DNA-DNA hybridization data were obtained, and the physiological and biochemical profile is different, we are talking about three different strains of Bacillus subtilis. Sequence analysis of the 16S rRNA gene of bacterial strain 3 showed that it belongs to the class Pseudomonadaceae, genus Pseudomonas, to the species Pseudomonas chlororaphis and has a high level of similarity ( 99.6\%) with the type strain Pseudomonas chlororaphis DSM 50083T. Sequence analysis of the $16 \mathrm{~S}$ rRNA gene of bacterial strain 25 showed that it belongs to the class Bacceliaceae, genus Bacillus and has a high level of similarity $(\sim 99.6 \%)$ with the Bacillus aryabhattai strain K13.

\subsection{Biochemical characteristics of soil strains}

Determination of biochemical characteristics of cultures using API $20 \mathrm{E}$ and API $50 \mathrm{CH}$ tests revealed the following features. The biochemical profile of strains 18, 27, 28 was almost identical to each other and very close to the species Bacillus subtilis ATCC $6051^{\mathrm{TM}}$. All three strains were urease negative. They showed the ability to liquefy gelatin, utilize citrates, as well as a wide range of carbon sources, namely, glycerol, L-arabinose, D-ribose, D-xylose, D-glucose, D-fructose, D-mannose, inositol, D-mannitol, D-sorbitol, salicin, D-cellobiose, D-maltose, D-melibiose, D-sucrose, Dtrehalose, inulin. The studed strains cleaved potassium 2-ketogluconate and potassium 5ketogluconate, and also showed pronounced hydrolytic activity with respect to starch and glycogen, weak with respect to turanose. 
Strain 25 , in contrast to strains $18,27,28$, showed the ability to utilize D-galactose and erythritop, but not inositol and inulin. The strain had $\beta$-galactosidase and also possessed ability to degrade $\mathrm{N}$ acetylglucosamine, that indicate on its potential antimicrobial activity.

Strain 3 utilized a wide range of organic substrates, but did not hydrolyze starch, glycogen and xylitol; did not exhibit $\beta$-galactosidase and $\mathrm{N}$-acetylglucoseamine enzyme activities.

\subsection{Features of the morphology of Bacillus aryabhattai 25}

A number of unique morphological features of the bacterium B. aryabhattai 25 were identified by morphometric analysis of phase contrast images of the cells (Fig 2,3). The bacterium B. aryabhattai 25 is distinguished by an unusual form of morphological rearrangements of cells in the cycle of culture development. Strain 25, in the process of exponential growth, forms chains of cells of irregular shape, which on the first day of growth on rich nutrient media are filled with multiple refractory granules of unknown nature (Fig. 2a).
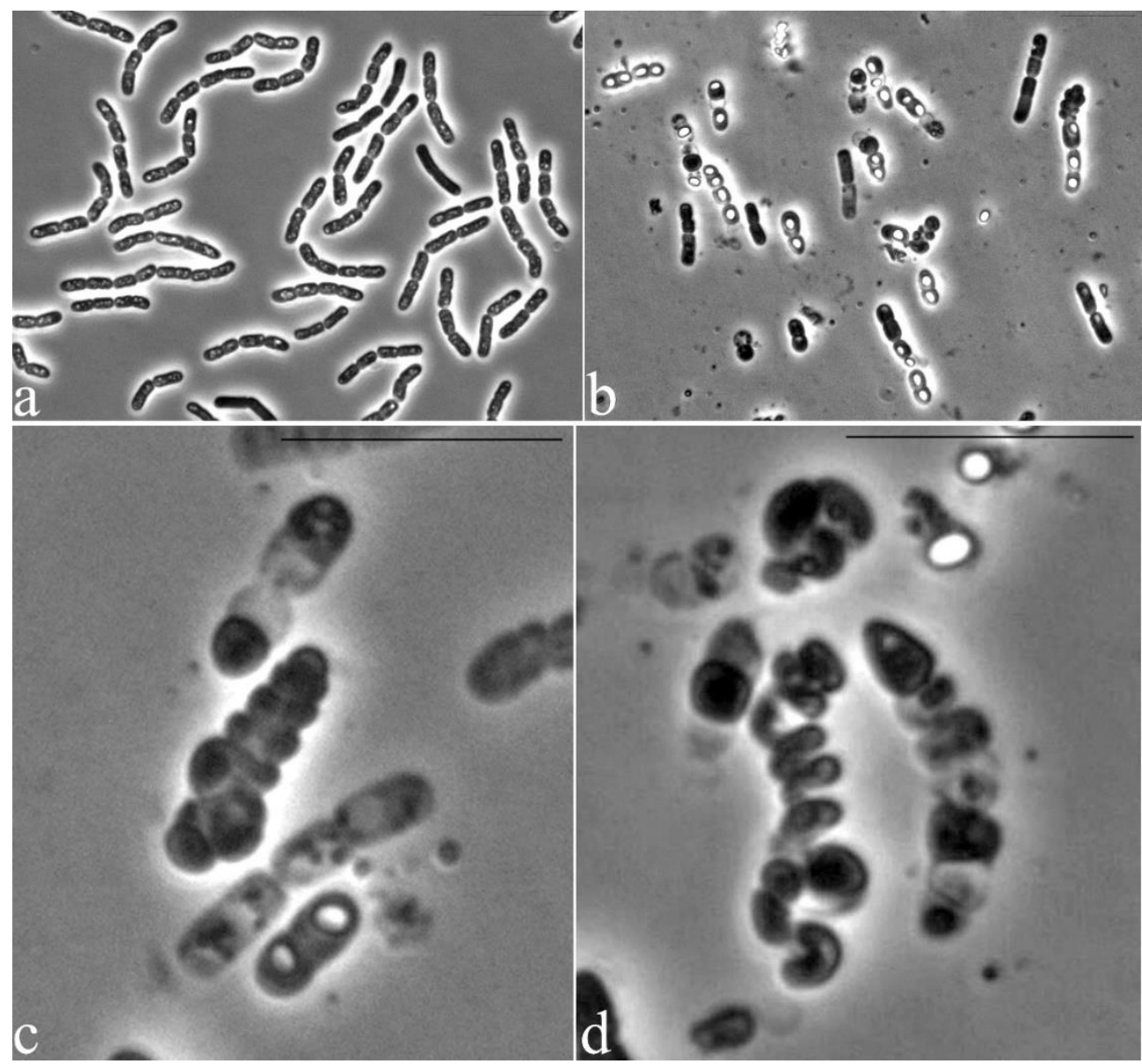

Figure 2. Bacillus aryabhattai str. 25 in the exponential growth phase (a - 1 day of growth; $b-2$ days of growth). Light microscopy. Phase contrast. Bar $-10 \mu \mathrm{m}$.

On the second day of growth, the process of sporulation begins. During this phase of growth, some cells within the cell chain begin to divide in a fragmented manner, forming clusters of multiple small and ultrasmall irregular cell forms (Fig. 2 b, c). Some of the ultrasmall cells in the clusters form spores (Fig. 2b), and some form spirally twisted cords, in which septa are subsequently formed, followed by fragmentation into ultra-small cell forms (Fig. 2d). The formation of chaotically oriented cell walls in the cytoplasm can be seen on an ultrathin section of the growing strain 25 cell. There is an uneven division by the type of fragmentation, which is accompanied by the formation of small, up to $0.5 \mu \mathrm{m}$, and very small, around $0.3 \mu \mathrm{m}$, cells (Fig. 3). 


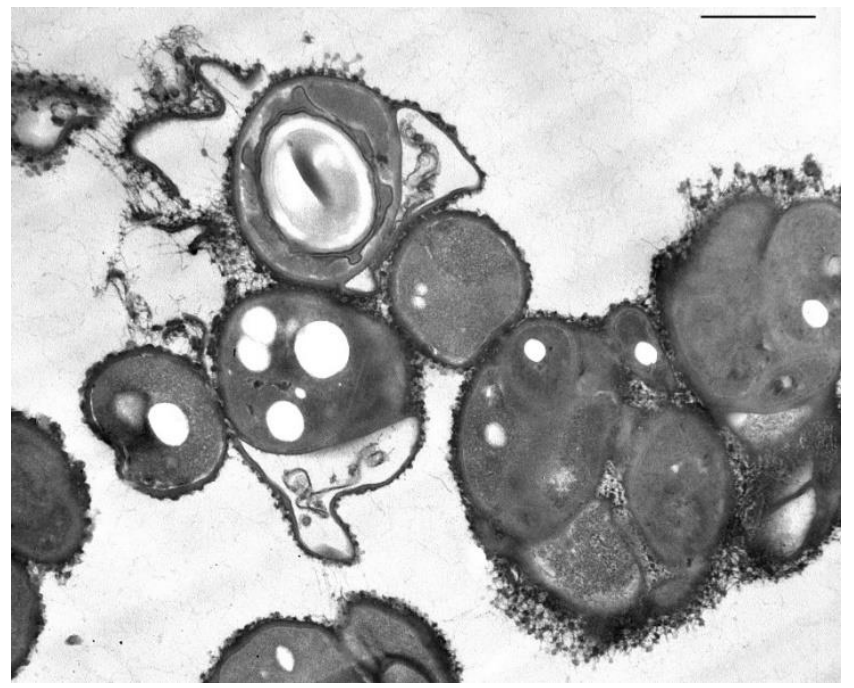

Figure 3. Ultrathin section of cleaving cells of Bacillus aryabhattai str. 25 in a conglomerate (bunch). Some cells in the conglomerate are ultrasmall (less than $300 \mathrm{~nm}$ in diameter). Transmission Electron Microscopy. Bar $-1 \mu \mathrm{m}$.

The B. aryabhattai strain 25 is of great interest for understanding the processes of survival, colonization of plant roots and the implementation of the interaction between the bacterium and the host plant. Analysis of the genomes of this bacterial species showed that most of them carry genes responsible for stimulating plant growth [17]. The peculiarity of strain 25, realized in the development cycle, to split into multiple ultra-small forms, can contribute to the rapid and effective colonization of the rhizosphere of agricultural plants.

\section{Conclusion}

As a result of the study, a number of bacterial strains were isolated from the soil according to their ability to degrade benzoate. Some of these strains have proven to be antagonists of fungal phytopathogens. Particularly noteworthy is the P. chlororaphis 3 strain, which was characterized by a pronounced ability to control the growth of fungal phytopathogens with comparable efficiency with the best bacterial strains used in biological products. In addition, the conducted microscopic studies made it possible to find the B. aryabhattai strain 25 , which significantly differs in its cytological and morphological characteristics from all known representatives of this genus. Thus, both biotechnologically significant strains and strains reflecting the microbial diversity of soil microflora were obtained. Further studies of their properties are ongoing.

Funding: This research was funded by RFBR according to the research project № 19-54-80003.

Conflicts of Interest. The authors declare no conflict of interest in financial or any other sphere.

Ethical approval. This article does not contain description of studies with human participants or animals performed by any of the authors.

Author Contributions: conceptualization, I.S.; methodology, I.S., T.O.A., N.S., T.N.A; validation, T.E., N.S. and I.S.; formal analysis, T.O.A.; investigation, T.O.A, T.E., T.N.A., N.E., I.S.; writing-original draft preparation, T.O.A., T.E., T.N.A., N.S., I.S.; writing-review and editing, T.O.A., T.E., T.N.A., N.S., I.S.; visualization, T.E., I.S; supervision, I.S.; project administration, I.S.; funding acquisition, I.S.

\section{References}

1. Daniel, R. The metagenomics of soil. Nature Rev. Microbiol. 2005, 3 (6), 470-478. doi:10.1038/nrmicro1160.

2. Zegeye, E.K.; Brislawn, C.J.; Farris, Y.; Fansler, S.J.; Hofmockel, K.S.; Jansson, J.K.; Wright, A.T.; Graham, E.B.; Naylor, D.; McClure, R.S.; Bernstein, H.C. Selection, succession, and stabilization of soil microbial consortia. mSystems 2019, 4, e00055-19. https://doi.org/10.1128/mSystems.00055-19. 
3. Sutton, N.B.; Maphosa, F.; Morillo, J.A.; Abu Al-Soud, W.; Langenhoff, A.A.M.; Grotenhuis, T.; Rijnaarts, H.H.M.; Smidt, H. Impact of long-term diesel contamination on soil microbial community structure. Appl. Environ. Microbiol. 2013, 79(2), 619-630. doi:10.1128/aem.02747-12.

4. Balderas-Ruíz, K.A.; Bustos, P.; Santamaria, R.I.; González, V.; Cristiano-Fajardo, S.A.; Barrera-Ortíz, S.; Mezo-Villalobos, M.; Aranda-Ocampo, S.; Guevara-García, A.A.; Galindo, E.; Serrano-Carreón, L. Bacillus velezensis 83 a bacterial strain from mango phyllosphere, useful for biological control and plant growth promotion. AMB Expr. 2020, 10, 163. https://doi.org/10.1186/s13568-020-01101-8.

5. Gamalero, E.; Favale, N.; Bona, E.; Novello, G.; Cesaro, P.; Massa, N.; Glick, B.R.; del Carmen OrozcoMosqueda, M.; Berta, G.; Lingua, G. Screening of bacterial endophytes able to promote plant growth and increase salinity tolerance. Appl. Sci. 2020, 10, 5767; doi:10.3390/app10175767.

6. Souza, R.d; Ambrosini, A.; Passaglia, L.M. Plant growth-promoting bacteria as inoculants in agricultural soils. Genet. Mol. Biol. 2015, 38, 401-419. doi: 10.1590/S1415-475738420150053.

7. Lucy, M.; Reed, E.; Glick, B.R. Applications of free living plant growth-promoting rhizobacteria. Antonie Van Leeuwenhoek 2004, 86, 1-25. doi: 10.1023/B:ANTO.0000024903.10757.6e.

8. Gouda, S.; Kerry, R.G.; Das, G.; Paramithiotis, S.; Shin, H.S.; Patra, J.K. Revitalization of plant growth promoting rhizobacteria for sustainable development in agriculture. Microbiol. Res. 2018, 206, 131-140. doi: 10.1016/j.micres.2017.08.016.

9. Kozhemyakov, A.P.; Belobrova, S.N.; Orlova, A.G. Creating and analyzing a database on the efficiency of microbial preparations of complex action. Agricultural biology (in Russian) 2011, 3, 112-115.

10. Zhukov, V.A.; Shtark, O.Y.; Borisov, A.Y.; Tikhonovich, I.A. Breeding to improve symbiotic effectiveness of legumes. In Plant Breeding from Laboratories to Fields; Andersen, S.B., Ed.; Rijeka, Croatia, 2013, pp. 167207. doi: 10.5772/53003.

11. Sambrook, J.; Fritsch, E.F.; Maniatis, T. Molecular Cloning: A Laboratory Manual; Cold Spring Harbor Laboratory Press, 1989; 479.

12. Ownley, B.H.; Weller, D.M.; Thomashow, L.S. Influence of in situ and in vitro pH on suppression of Gaeumannomyces graminis var. tritici by Pseudomonas fluorescens 2-79. Phytopathology 1992, 82, 178-184.

13. Lane, D.J. 16S/23S rRNA sequencing, In: Nucleic acid techniques in bacterial systematic, Stackebrandt, E., Goodfellow, M., eds; John Wiley and Sons: New York, NY, 1991, pp. 115-175.

14. Thompson, J.D.; Higgins, D.G.; Gibson, T.J. CLUSTAL W: improving the sensitivity of progressive multiple sequence alignment through sequence weighting, position-specific gap penalties and weight matrix choice, Nucleic Acids Res., 1994, 22, 4673-4680, doi: 10.1093/nar/22.22.4673.

15. Reynolds, E.S. The use of lead citrate at high $\mathrm{pH}$ as an electron-opaque stain in electron microscopy. .J. Cell. Biol. 1963, 17, 208-213.

16. Siunova, T.V.; Anokhina, T.O.; Sizova, O.I.; Sokolov, S.L.; Sazonova, O.I.; Kochetkov, V.V.; Boronin, A.M.; Patil, S.G.; Chaudhari, A.B. PGPR Pseudomonas strains promising for the development of bioformulations for plant protection and stimulation. Biotechnologia (in Russian) 2017, 33, 56-67. doi: 10.1016/0234-27582017-33-2-56-67.

17. Bhattacharyya, C.; Bakshi, U.; Mallick, I.; Mukherji, S.; Bera, B.; Ghosh A. Genome-guided insights into the plant growth promotion capabilities of the physiologically versatile Bacillus aryabhattai strain AB211. Front. Microbiol. 2017, 8, 411. www.frontiersin.org.

Publisher's Note: MDPI stays neutral with regard to jurisdictional claims in published maps and institutional affiliations.

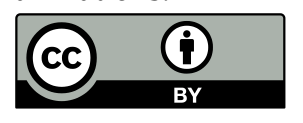

(C) 2020 by the authors; licensee MDPI, Basel, Switzerland. This article is an open access article distributed under the terms and conditions of the Creative Commons Attribution (CC-BY) license (http://creativecommons.org/licenses/by/4.0/). 